\title{
Survival of asbestos insulation workers with mesothelioma
}

\author{
Joseph Ribak, Irving J Selikoff
}

\begin{abstract}
Malignant mesothelioma is a lethal disease. It is rare in the general population; however, workers exposed to asbestos suffer significant burdens of the neoplasm. The survival time of 457 consecutive fatal cases of pleural and peritoneal mesothelioma that occurred among 17800 asbestos insulation workers observed prospectively from 1 January 1967 to 1 January 1987 was studied. Mean survival time from initial presentation of the disease to death was 11.4 months for the pleural mesothelioma patients compared with 7.4 months for the peritoneal group. This difference was statistically significant. Mean survival time from diagnosis to death was shorter for both groups of patients: 8.4 months for pleural mesothelioma $v \mathbf{5 . 8}$ months for the peritoneal cases. In conclusion, survival time in mesothelioma patients is short; most die within a year from the onset of the initial symptoms. No effective therapy is yet available.
\end{abstract}

Malignant mesothelioma is very rare in the general population without documented exposure to asbestos; however, groups with such exposure suffer significant burdens of the neoplasm..$^{1-3}$ Among them, it is a lethal disease with no effective therapy currently available. ${ }^{134-6}$ For these reasons there are important efforts to develop useful treatment programmes.

Because therapy is of little or no benefit to the disease, emphasis should be placed on its aetiology in the hope that identifying causes of the neoplasm may lead to prevention - for instance, by way of developing methods for modifying the biological activity of the retained fibrous agent in already exposed workers in whom the malignant disease process has not yet started. $^{78}$

Materials and methods

We investigated the clinical course of 457 con-

Environmental Sciences Laboratory, Mount Sinai School of Medicine, of the City University of New York, USA

Joseph Ribak, Irving J Selikoff secutive fatal cases of pleural and peritoneal mesothelioma that occurred among 17800 asbestos insulation workers observed prospectively from 1 January 1967 to 1 January 1987 . These accounted for $9 \cdot 1 \%$ of the 5026 deaths recorded.

The cohort was established in 1967 and included all members of the International Association of Heat and Frost Insulators and Asbestos Workers in the United States and Canada. On 1 January of that year, detailed information was recorded for these workers, including date of birth, onset of insulation work, clinical state, and smoking history.' Observation of the cohort was maintained with the assistance and cooperation of the local unions of the International Association. Whenever a member died, of whatever cause, the union officials notified both their Washington headquarters and our research clinic. In most cases, death certificates were also forwarded (as these were generally sought by the union for pension fund purposes); where not available, they were obtained from the health department of the state or province in which the death occurred. Requests were then made to hospitals, treating physicians, pathology laboratories-all who had been involved in the care of the patient-for available clinical data, $x$ rays, histopathological material (surgical, necropsy), with assurance of confidentiality. Such rapid notification and early request facilitated assembly of data. It is of interest, for purposes of the present report, that requests for information were also made to next of kin (usually the wife). This was primarily for identification of physicians who had treated the patient or hospitals in which treatment had been given, and for authorisation to seek data. These inquiries also elicited much information unique to personal observation. Though this was not used in the scientific evaluation of the illness, it did add to our knowledge of early symptoms, such as when working became a burden, or weight loss began, or when physicians were first consulted for still obscure complaints.

All available clinical, radiological, and histopathological materials were reviewed. For most cases in this series, pathological evaluation was made by Professor Yasunosuke Suzuki, head of our pathology unit; where necessary special histochemical and immunocytochemical studies were undertaken. 


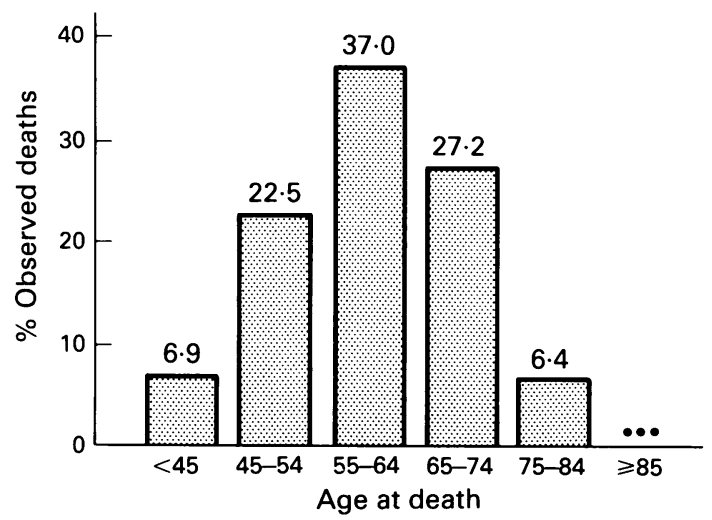

Figure 1 Per cent of deaths from pleural mesothelioma by age.

Comparisons of deaths were made in two waysthose recorded on death certificates (DC) and those ascertained by review of clinical and pathological material (best evidence, $\mathrm{BE}$ ). The rationale for such an approach has been discussed. ${ }^{2}$ There was only one exception to the foregoing: for pleural and peritoneal mesothelioma, no case was so categorised unless the histological material was reviewed by our pathologists (Drs J Churg, M Kannerstein, Y Suzuki) and so designated. ${ }^{39}$ Other deaths were diagnosed as mesothelioma (on death certificates, or in medical or pathology records, or both) but where slides were not available for review, the case was not included as mesothelioma in our series, even if the clinical findings were consistent with such diagnosis.

By the end of 1976, 2221 deaths had occurred. ${ }^{1}$ With continued observation, 5026 were recorded by the end of 1986 . Using the admittedly restrictive categorisation criteria noted above, 457 cases of malignant mesothelioma occurred between 1967 and 1986 (186 pleural and 271 peritoneal). Figures 1-3

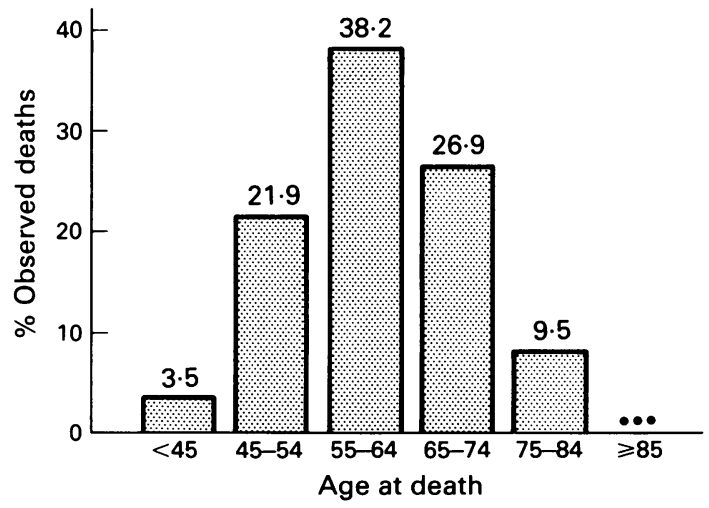

Figure 2 Per cent of deaths from peritoneal mesothelioma by age.

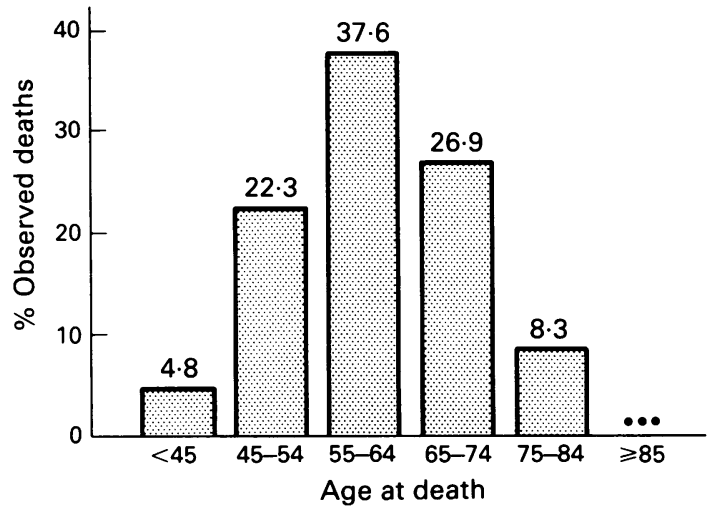

Figure 3 Per cent of deaths from pleural and peritoneal mesothelioma by age.

indicate that approximately two thirds of the patients died before age 65 . Data concerning survival time from first symptom to death and from diagnosis to death were analysed, including treatment modalities.

\section{Results}

Table 1 presents the survival time (in months) from initial symptom (the first symptom related to mesothelioma as found in the patient's records or in a description in a letter written by his next of $\mathrm{kin}^{2}$ to death of patients with malignant pleural and peritoneal mesothelioma. In pleural mesothelioma, mean survival time was 11.4 months and median time 10 months. Survival time in peritoneal patients was shorter (mean 7.4 months). Within a year from first symptom $63.4 \%$ of the pleural patients and $86.3 \%$ of the peritoneal patients were dead. The difference in survival time between the pleural and peritoneal groups was statistically significant (generalised Wilcoxon test $(p<0.001)$. There were 10 patients with pleural mesothelioma and six peritoneal cases who survived for more than two years.

Table 2 presents survival times from diagnosis of mesothelioma to death in the same patients. It can be clearly seen that such survival time was shorter. Median time for pleural patients was five months and for peritoneal cases only two months. Again, differences in survival time was statistically highly significant.

In Table 3 we present the different treatment modalities of patients in our cohort. Chemotherapy was the most frequent treatment used, either alone or in combination with surgery and radiotherapy. Surgery was more frequent in the patients with pleural mesothelioma.

We found no differences for survial time, either from diagnosis to death or from first symptom to death, between the various treatment modalities or between treated and untreated patients. 
Table 1 Survival time (in months) from initial symptoms to death in 385 consecutive cases of mesothelioma among asbestos insulation workers, $1967-86$

\begin{tabular}{|c|c|c|c|c|c|c|}
\hline \multirow{2}{*}{$\begin{array}{l}\text { Survival } \\
\text { (months) }\end{array}$} & \multicolumn{3}{|c|}{ Pleural mesothelioma } & \multicolumn{3}{|c|}{ Peritoneal mesothelioma } \\
\hline & No & $\%$ & Cum \% & No & $\%$ & Cum \% \\
\hline $\begin{array}{c}1-3 \\
4-6 \\
7-9 \\
10-12 \\
13-18 \\
19-24 \\
25-30 \\
31-36 \\
>36\end{array}$ & $\begin{array}{r}28 \\
22 \\
12 \\
28 \\
26 \\
16 \\
4 \\
4 \\
1\end{array}$ & $\begin{array}{r}19.9 \\
15.6 \\
8.5 \\
19.9 \\
18.4 \\
11.4 \\
2.8 \\
2.8 \\
0.7\end{array}$ & $\begin{array}{r}19.9 \\
35.5 \\
44.0 \\
63.9 \\
82.3 \\
93.7 \\
96.5 \\
99.3 \\
100.0\end{array}$ & $\begin{array}{r}63 \\
70 \\
52 \\
29 \\
17 \\
9 \\
2 \\
1 \\
1\end{array}$ & $\begin{array}{r}25.8 \\
28.7 \\
21.3 \\
11.9 \\
7.0 \\
3.7 \\
0.8 \\
0.4 \\
0.4\end{array}$ & $\begin{array}{r}25 \cdot 8 \\
54 \cdot 5 \\
75 \cdot 8 \\
87 \cdot 7 \\
94 \cdot 7 \\
98 \cdot 4 \\
99 \cdot 2 \\
99 \cdot 6 \\
100 \cdot 0\end{array}$ \\
\hline Total & 141 & $100 \cdot 0$ & $100 \cdot 0$ & 244 & $100 \cdot 0$ & $100 \cdot 0$ \\
\hline
\end{tabular}

Mean survival for patients with pleural mesothelioma 11.4 (SD 7.8) months; median 10 months. Mean survival for patients with peritoneal mesothelioma $7 \cdot 4$ (SD 5.8) months; median four months.

${ }^{\star}$ In 45 cases of pleural mesothelioma and in 27 cases of peritoneal mesothelioma adequate information about survival time from initial symptom to death was not available.

Table 2 Survival time (in months) from diagnosis to death in 398 consecutive cases of mesothelioma among asbestos insulation workers, $1967-86$

\begin{tabular}{|c|c|c|c|c|c|c|}
\hline \multirow{2}{*}{$\begin{array}{l}\text { Survival } \\
\text { (months) }\end{array}$} & \multicolumn{3}{|c|}{ Pleural mesothelioma } & \multicolumn{3}{|c|}{ Peritoneal mesothelioma } \\
\hline & No & $\%$ & Cum \% & No & $\%$ & Cum \% \\
\hline $1-3$ & 56 & $40 \cdot 0$ & $40 \cdot 0$ & 179 & $69 \cdot 4$ & $69 \cdot 4$ \\
\hline $4-6$ & 20 & $14 \cdot 3$ & $54 \cdot 3$ & 40 & 15.5 & 84.9 \\
\hline $7-9$ & 14 & 10.0 & $64 \cdot 3$ & 17 & $6 \cdot 6$ & 91.5 \\
\hline $10-12$ & 19 & 13.6 & 77.9 & 6 & $2 \cdot 3$ & 93.8 \\
\hline $13-18$ & 19 & $13 \cdot 6$ & 91.5 & 11 & $4 \cdot 3$ & $98 \cdot 1$ \\
\hline $19-24$ & 7 & $5 \cdot 0$ & 96.5 & 4 & $1 \cdot 3$ & 99.4 \\
\hline $25-30$ & 2 & 1.4 & 97.9 & 1 & $0 \cdot 3$ & 99.7 \\
\hline $31-36$ & 2 & 1.4 & $99 \cdot 3$ & $i$ & $0 \cdot 3$ & $100 \cdot 0$ \\
\hline$>36$ & 1 & $0 \cdot 7$ & $100 \cdot 0$ & - & - & - \\
\hline Total & 140 & $100 \cdot 0$ & $100 \cdot 0$ & 259 & $100 \cdot 0$ & $100 \cdot 0$ \\
\hline
\end{tabular}

Mean survival for patients with pleural mesothelioma 8.4 (SD 5.3) months; median five months. Mean survival for patients with peritoneal mesothelioma $5 \cdot 8$ (SD $2 \cdot 6$ ) months; median two months.

^In 46 cases of pleural mesothelioma and in 13 cases of peritoneal mesothelioma adequate information about survival time from diagnosis to death was not available.

\section{Discussion}

Mesothelioma is a highly malignant and lethal disease. Survival time is usually short, although there are some anecdotal reports of long survival, usually case reports. ${ }^{10-12}$ This seems to be the exception and not the rule. Survival time in pleural patients is significantly longer than that of peritoneal mesothelioma patients, but lead time bias (because of relatively earlier diagnosis of pleural mesothelioma) must be considered.

Our results obtained from workers exposed to asbestos are in accordance with other studies. Dorward and Stack ${ }^{13}$ reported average survival of 40 weeks from diagnosis to death in thirty two pleural mesothelioma patients who had worked with asbestos. Treatment was not effective. Martinson et al ${ }^{14}$ found median survival of 11 months in pleural mesothelioma patients. Volgelzang et al ${ }^{15}$ reported on median survival of eight months in 31 cases of pleural and peritoneal mesothelioma treated at the University of Minnesota. Elmes ${ }^{16}$ in 63 asbestos exposed cases, found an average survival of 13.7 months from first symptoms to death in pleural mesothelioma patients and only 9.6 months from diagnosis to death. Results of other studies were similar. ${ }^{1718}$ Survival of asbestos workers in this

Table 3 Treatment modalities in mesothelioma patients among asbestos insulation workers, 1967-86

\begin{tabular}{|c|c|c|c|c|}
\hline & \multicolumn{2}{|c|}{ Pleural } & \multicolumn{2}{|c|}{ Peritoneal } \\
\hline & No & $\%$ & No & $\%$ \\
\hline Chemotherapy & 31 & $22 \cdot 6$ & 101 & $46 \cdot 2$ \\
\hline Radiotherapy & 21 & $15 \cdot 3$ & 10 & $4 \cdot 6$ \\
\hline Surgery & 13 & $9 \cdot 4$ & 5 & $2 \cdot 3$ \\
\hline Chem + Rad + Surg & 3 & $2 \cdot 2$ & 2 & 0.9 \\
\hline Chem + Rad & 17 & $12 \cdot 3$ & 16 & $7 \cdot 3$ \\
\hline Chem + Surg & 6 & $4 \cdot 7$ & 3 & 1.4 \\
\hline $\operatorname{Rad}+$ Surg & 2 & 1.4 & - & - \\
\hline No therapy & 44 & $32 \cdot 1$ & 82 & $37 \cdot 3$ \\
\hline Total & 137 & $100 \cdot 0$ & 219 & $100 \cdot 0$ \\
\hline
\end{tabular}

$\star$ In 47 pleural patients and in 51 peritoneal patients adequate information on treatment was not available. 
cohort, exposed to chrysotile or chrysotile and amosite, was much the same as for factory workers exposed to amosite. ${ }^{19}$

In accordance with other investigators, ${ }^{13-16}$ we could not show that any modality of treatment had a significant effect on survival time, which in any event is short. Neither chemotherapy alone nor when given in combination with surgery or radiation had a measurable effect on survival, most patients dying within a year of initial symptoms. Some hold that if patients are asymptomatic and stable, clinical therapy should be withheld as it is not effective to any measurable degree. We concluded that survival time is short, most patients die within a year of initial symptoms, and that no effective therapy is yet available.

Requests for reprints to: $\mathrm{Dr}$ Joseph Ribak, Occupational Health \& Rehabilitation, Institute at Loewenstein Hospital, PO Box 3, Raanana 43100, Israel.

1 Selikoff IJ, Hammond EC, Seidman H. Mortality experience of insulation workers in the United States and Canada 19431976. Ann NY Acad Sci 1979;330:91-116.

2 Ribak J, Lilis R, Suzuki Y, Penner L, Selikoff IJ. Malignant mesothelioma in a cohort of asbestos insulation workers: Clinical presentation, diagnosis and causes of death. $\mathrm{Br} J$ Ind Med 1988;45:182-7.

3 Selikoff IJ, Churg J, Hammond EC. Asbestos exposure and neoplasia. JAMA 1964;188:22-6.

4 Nurminen $M$. The epidemiologic relationship between pleura mesothelioma and asbestos exposure. Scand $J$ Work Environ Health 1975;1:128-37.
5 Chahinian AP, Pajak TF, Holland JF, Norton L, Ambinder RM, Mandel EM. Diffuse malignant mesothelioma: Prospective evaluation of 69 patients. Ann Intern Med 1982;96: 746-55.

6 Adams VI, Unni KK, Muhm JR, Jett JR, Ilstrup DM, Bernatz PE. Diffuse malignant mesothelioma of pleura: Diagnosis and survival in 92 cases. Cancer 1986;58:1540-51.

7 De Wys WD, Malone WF, Butrum RR, Sestilli MA. Clinical trials in cancer prevention. Cancer 1986;58:1954-62.

8 Schiffman MH, Pickle LW, Fontham E, et al. Case-control study of diet and mesothelioma in Luisiana. Cancer Res 1988;48:2911-5.

9 Suzuki Y. Pathology of human malignant mesothelioma. Semin Oncol 1981;8:268-82.

10 Blake PR, Catterall M, Emerson PA. Pleural mesothelioma treated by fast neutron therapy. Thorax 1985;90:72-3.

11 Brenner J, Sordillo PP, Magill GB. Seventeen year survival in a patient with malignant peritoneal mesothelioma. Clinical Oncology 1981;7:249-51.

12 Brenner J, Sordillo PP, Magill GB. An unusual presentation of malignant mesothelioma; the incidental finding of a tumor in the hernia sac during herniorrhaphy. J Surg Oncol 1981; 18:159-61.

13 Dorward AJ, Stack BH. Diffuse malignant pleural mesothelioma in Glasgow. British Journal of Diseases of the Chest 1981; 75:397-402.

14 Martensson G, Hagmar B, Zettergren L. Diagnosis and prognosis in malignant pleural mesothelioma. A prospective study. European Journal of Respiratory Diseases 1984;65:169-78.

15 Vogelzang NJ, Schultz SM, Iannucci AM, Kennedy BJ. Malignant mesothelioma-the University of Minnesota experience. Cancer 1984;53:377-83.

16 Elmes PC. The natural history of mesothelioma of the pleura. Journal of the Irish Colleges of Physicians and Surgeons 1972;1: 117-23.

17 Antman KH. Malignant mesothelioma. New Engl J Med 1980;303:200-2.

18 Wagner JC, Slegges CA, Marchand P. Diffuse pleural mesothelioma and asbestos exposure in the North Western Cape Province. Br J Ind Med 1960;17:260-71.

19 Ribak J, Seidman H, Selikoff IJ. Amosite mesothelioma in a cohort of asbestos workers. Scand $J$ Work Environ Health 1989;15:84-100.

Accepted 20 January 1992 